\title{
Human-Agent Negotiations: The Impact of Agents' Concession Schedule and Task Complexity on Agreements
}

\author{
Rustam Vahidov, Gregory E. Kersten, Bo Yu \\ J. Molson School of Business, Concordia University, Montreal, Canada \\ \{rustam.vahidov; gregory.kersten; bo.yu\}@concordia.ca
}

\begin{abstract}
Employment of software agents for conducting negotiations with online customers promises to increase the flexibility and reach of the exchange mechanism and reduce transaction costs. Past research had suggested different negotiation tactics for the agents, and had used them in experimental settings against human negotiators. This work explores the interaction between negotiation strategies and the complexity of the negotiation task as represented by the number of negotiation issues. Including more issues in a negotiation potentially allows the parties more space to maneuver and, thus, promises higher likelihood of agreement. In practice, the consideration of more is-sues requires higher cognitive effort, which could have a negative effect on reaching an agreement. The results of humanagent negotiation experiments conducted at a major Canadian university revealed that there is an interaction between chosen strategy and task complexity. Also, when competitive strategy was employed, the agents' utility was the highest. Because competitive strategy resulted in fewer agreements the average utility per agent was the highest in the compromising-competitive strategy.
\end{abstract}

Keywords: human-agent negotiations, software agents, strategies, concessions, multi-attribute utility, experiments, task complexity

\section{Introduction}

Negotiations can be conducted online by using e-negotiation systems. E-negotiation systems can facilitate the communication of participating parties and offer a variety of decision aids [1]. These systems can flexibly organize negotiations in certain relational structures and sequential processes of exchange. They can impose the format of the exchanged offers and provide analytical support for negotiators in different phases. These features make e-negotiation systems different from general communication tools, such as e-mail and Internet messengers. Typically, these systems provide support to their users by helping them capture and model their objectives, preferences, reservation levels, and other important aspects. While the system features can smooth negotiation processes and reduce negotiators' efforts, the negotiators are still responsible for the negotiation outcomes, as they need to engage in repetitive decision-making, interact with other negotiators, assess incoming offers, and construct counter-offers.

Autonomous software agents become increasingly popular in e-commerce. They participate in a variety of commercial activities [2] [3]. Designing and offering software agents that are capable of conducting negotiations has been a persistent interest of the software-agent research community [4]. When software agents are employed to conduct commerce negotiations, technology takes an active role of determining social affairs.

A distinguishing feature of negotiation is that negotiators need to resolve mutual dependencies. Negotiation agreements depend on the other negotiators' choices. Thus, conducting fully automated negotiations for business transactions is tricky, as the resulting commitment when an agreement is achieved may not be desirable to the principal businesses or individuals.

On the other hand, employment of agents in negotiations can be beneficial due to the fact that software agents have computational advantages as compared to human negotiators. Software agents can operate faster and potentially optimize the outcome given the information available to them. They do not get distracted, which is very different from humans whose decisions are influenced by their selective attention. In addition, agent behavior is less biased and more consistent than that of humans [5]. When an agent receives a negotiation task specified in terms of negotiation issues, preferences, reservation levels, and the concession-making strategies, it will negotiate precisely in accordance with these specifications.

Employing software agents to negotiate with others can have additional benefits. For instance, agents can reduce negotiation-related efforts, help people with limited negotiation skills [6], save time with lower opportunity costs, 
alleviate negative effects, and achieve more efficient settlements [7]. The design of software agents that are capable of negotiating has been focusing primarily on engineering aspects. Empirical studies of how agents perform when negotiating with human negotiators remain rare.

This work investigates the performance of agent-to-human negotiations when tactics adopted by agents and task complexity vary. The work attempts to explore the prospects of employing software agents to conduct real business transactions. An experiment was conducted by manipulating agent negotiation style and negotiation-task complexity.

An electronic negotiation system, which enables the creation of negotiation cases, setting up multiple negotiation issues and preference structures, defining negotiation tactics for agents, as well as other functions was built for the experiment. Software agents and human negotiators were paired in negotiation dyads, which then negotiated on an either simple or complex business case. The results reveal that agent-negotiation tactics and task complexity have an interaction effect. Specifically, agents that used a competitive tactic reached more agreements in the simple case than in the complex case. A similar effect was absent when agents adopt a compromising tactic.

The paper builds on and extends the work presented in [8]. It has five more sections. Prior work on the design of and experiments with software agents is discussed in Section 2. Negotiation strategies are introduced in Section 2. Concessions are one of the key component of strategy. The design of the concession schedules that agents can employ is also discussed in this section. The agent-human negotiation experiment is discussed in Section 4 and it is followed by the presentation of the experiment results. Conclusions and future work complete the paper.

\section{Background}

One of the first experiments involving agent negotiations involved Kasbah marketplace [9, 10]. In these experiments users created simple agents that were dispatched to meet and negotiate with each other on price only for items. The agents incorporated three types of negotiation concession tactics. These tactics are used to decide what kind of offer to make at a given point in the negotiation process.

Faratin, Sierra and Jennings [11], in an influential study that build on the Kasbah experiments, proposed formal representation of the agent negotiation strategies of which concession tactics were a key component. The choice of concession tactic based on the negotiation history and context, deadline and other variables. This allowed the agent to employ different tactics within a single strategy.

Three categories of tactics have been identified: behavior-dependent, time-dependent, and resource-dependent. The behavior-dependent tactics make their choice of offer based on the moves made by the parties. An example includes tit-for-tat tactics that advocate that the concession to be made by a party should be proportional, or symmetrical to the one made by the counterpart.

The second family of tactics model concession-making as a function of time elapsed between the beginning of negotiation and the estimated ending point. Curves showing small concessions in the beginning corresponded to tougher competitive behavior, while those making large concessions and quickly approaching the vicinity of reservation levels related to compromising behavior. Resourcedependent tactics adjusted concession levels based on the scarcity of the resources involved.

Regarding agent involvement in electronic negotiations, three categories can be mentioned: (1) human-to-human negotiations with agent support; (2) agent-to-agent negotiations featuring full automation on both sides of a table, and (3) human-to-agent negotiations, where a software agent is paired up with a human counterpart [7].

The first category includes use of agents as advisors for helping human negotiators cope with the complexity of negotiations involving multiple issues, and staying in line with their defined preference structures and concessionmaking plans. Work on Aspire agents [12] and eAgora marketplaces [13] are examples of the first category work. For instance, experiments with agent-supported negotiations revealed that human negotiators using agents as advisors performed better in complex (multi-issues) tasks than unassisted human negotiators [14].

Work in the second category, i.e., agent-to-agent negotiations, has been extensive and includes distributed AI, multi-agent systems and learning [see, e.g., 4, 15-18]. The current work falls into the third category in which both human and agents negotiated.

Early studies on human-agent negotiations deals with providing the agents with negotiation capabilities [19, 20]. Klein, Woods, et al. [21] discuss ten challenges for making software agents capable of participating in joint humanagent activities.

Major challenges of designing agents that can negotiated with humans include bounded rationality and incomplete information. Yang and Singhal [6] formulated guidelines for agent-designers have been proposed: randomization (to prevent manipulation of an agent by an opponent), having a concession strategy, and maintaining a database of past interactions (for modeling the opponents).

Chavez et al. [7] suggested several tactics that agents could employ in negotiations with humans. The suggested tactics were: making a tough initial offer; making two or more simultaneous equivalent (to an agent) offers; making monotonously decreasing concessions (as suggested by Raiffa [22] to signal "approaching the limit"); making large concessions in the final offer; and using strategic delays.

Few experimental studies involving humans and agents in exchange settings focusing on objective as well as subjective aspects of negotiations have been reported. An early experimental study matching humans with agent counterparts involved AutONA agents [23]. The agents negotiated on price and volume while following the so-called alphabeta tactics. The agents did not significantly outperform 
humans.

An agent representing a salesperson that employed persuasion and negotiation techniques while interacting with a customer is described in [24]. Persuasion involved customer - agent dialogue with the use of pre-defined arguments organized into a tree. Price was the single negotiated issue. The findings suggested that persuasion increased buyers' product valuation and willingness to pay, and negotiation increased the seller's surplus.

De Melo, Celso and Gratch [25] examined effects of agents' expression of emotions on the negotiator's concession behavior. In this study, human subjects were paired up with agents that expressed anger, neutrality, or happiness during negotiations. For that purpose, the agents used both with verbal and non-verbal expression mode. The subjects were aware that they were negotiating with machines. As expected, "angry" agents were able to gain more concessions from the human opponents than the "happy" ones.

In [26], the authors investigated effects of using various agent negotiation tactics in experiments with human subjects. In these bilateral negotiation experiments involving the sale of a computer five different concession-making styles were used: competitive, linear, compromising, competitive-then-compromising, and tit-for-tat. Agents were on the seller side, while humans were on the buyer side. A control group was included on the seller side, including human subjects. The results revealed that most agent types outperformed human "colleagues" in terms of utility of the achieved agreement and the agreement rate. Competitive agents achieved the highest utility levels, while compromising agents had the highest number of agreements.

Vahidov, Kersten and Gimon [27], agents were employed in multi-bilateral negotiation settings. Here, the case featured a procurement scenario with a single buyer and three sellers. The buyer would award a single contract to one of the sellers based on simultaneous negotiations with all three counterparts. While most of the participants were human subjects, agents were present in some of the seller groups. The results showed that compromising agents achieved higher agreement rates than humans, while competitive ones failed to win any contract.

\section{Negotiations strategies, tactics, and tasks}

In the current work, we set out to investigate the performance of agents not only based on the agent strategies, but also on the complexity of the negotiation task. The complexity is manipulated by varying the number of issues involved in the negotiation process.

\subsection{Negotiation strategies and tactics}

Scholars in negotiations as well as military and political sciences distinguish between strategies and tactics [28]. Strategies are relatively stable and are associated with the negotiator's attitude to conflict situations, negotiation context, skills and the importance of the conflict and its resolution, Negotiator's skills include the toolbox of methods for conflict assessment and its resolution. A tactic is the combination of concrete methods that are selected at any specific time of the negotiation process; they are contextand time-dependent [29].

In some situations, participants may employ a single tactic which is equivalent to a strategy. This is the case with software agents that employ a concession formula irrespectively of the changes in the negotiation context. When the agents use context-dependent messages, alter their concession patterns, or change their frequency of offers and/or messages, then they are likely to employ different tactics within a single strategy.

There are five well-known types of approaches to conflict [18], [30], three of which can be used to define negotiation strategies' types, i.e., competitive, compromising and collaborating. Collaborating strategies require that the negotiators make an effort in exchanging truthful information, including their preferences and trade-offs. This effort as well as the negotiators' unwillingness to provide their counterparts with truthful relevant information [31, 32 ] led us to focus on competitive and compromising strategies.

In addition to the two pure strategies we have also implemented two mixed strategies. The mixed strategies describe situations in which the negotiators at some point switch from their competitive (compromising) tactics and employ compromising (competitive) tactics.

\subsection{Task complexity}

Task complexity broadly refers to the effort required to perform the task [33] and it can be assessed based on three aspects: (1) syntactic difficulty; (2) cognitive complexity; and (3) communicative stress [34]. We are concerned here with the cognitive complexity measured against the number of the negotiation issues. A meta-analysis of the taskperformance relationship shows that increased complexity is negatively correlated with performance [35].

Increased complexity causes the negotiators to consider only a small subset of offers, which is likely to lead to poor agreements [36]. It also significantly contributes to a more frequent use of competitive tactics over compromising and collaborative tactics [37].

High cognitive task complexity, e.g., having a large number of issues that are preferentially interdependent, requires that the negotiators extend more effort and focus on the task. This may lead to a decrease of effort on the process and its progress. One approach to reduce complexity is to engage in issue-by-issue negotiations which is cognitively simpler but prone to abuse by the counterpart and may lead to inferior agreements $[38,39]$.

Decision and negotiation aids, including tools used for preference elicitation and utility function construction, help the negotiators to engage in negotiations, where they 
simultaneously consider multiple issues. This is the case in our experiments: both the agents and the human participants exchange offers that comprise values for all issues.

The focus here is on the agents' performance and the quality of the agreements they achieve. Following earlier studies, we analyze the relationship between the task complexity and the agreement quality (measured with utility). In addition, we compare the efficacy of negotiation strategies for different tasks.

\section{Negotiation experiment}

Two negotiation cases used in the experiments and the agents' concession schedules are discussed below.

\subsection{Negotiation case}

Two types of cases were included:

1. Simple cases involved the following five issues: price, regular air time, extra air time, text messaging, and data. The buyers and sellers were given both different and divergent preferences (weights) for these issues, indicating their importance levels.

2. Complex cases involved ten issues: in addition to the five issues of the simple case also call display, voicemail, call waiting, conference call, and call forwarding.

Figure 1 shows the screenshot for the setup of a simple case. The setup for the complex case was similar.

\begin{tabular}{|c|c|c|c|c|c|}
\hline Issue & Type & $\begin{array}{l}\text { Weight } \\
\text { S! B! }\end{array}$ & $\begin{array}{l}\text { Initially } \\
\text { Activated }\end{array}$ & & \\
\hline :i Price & Numeric & $\frac{40 \%}{60 \%}$ & Yes & $\underline{1}$ & \\
\hline Regular air time (7am to 7pm) & $\begin{array}{l}\text { Categorical (single } \\
\text { choice) }\end{array}$ & $\begin{array}{l}5 \% \\
10 \%\end{array}$ & Yes & $\underline{I}$ & î \\
\hline Extra air time (outside $7 \mathrm{am}$ to $7 \mathrm{pm}$ ) & $\begin{array}{l}\text { Categorical (single } \\
\text { choice) }\end{array}$ & $\begin{array}{l}5 \% \\
10 \%\end{array}$ & Yes & 1 & \\
\hline : Textmessaging & $\begin{array}{l}\text { Categorical (single } \\
\text { choice) }\end{array}$ & $\begin{array}{l}25 \% \\
10 \%\end{array}$ & Yes & 1 & \\
\hline : Data & $\begin{array}{l}\text { Categorical (single } \\
\text { choice) }\end{array}$ & $\begin{array}{l}25 \% \\
10 \%\end{array}$ & Yes & 2 & \\
\hline
\end{tabular}

Figure 1. Setup of the simple case

In order to calculate the total utility of the offer, the issues and the issue options were assigned weights. These weights were used in an additive utility function to estimate the level of attractiveness of an offer. Agents used this information in order to decide on the acceptability of the received offers and to generate offers.

\subsection{Strategies and concessions}

We have chosen four strategies for the agents: competitive, compromising, competitive-then-compromising, and compromising-then-competitive.

Each strategy was defined by two components: (1) a strategy configuration component; and (2) a concession curve component.

The screen used for strategy configuration for the agent is shown in Figure 2 and the concession curves are shown in Figures 3 and 4.

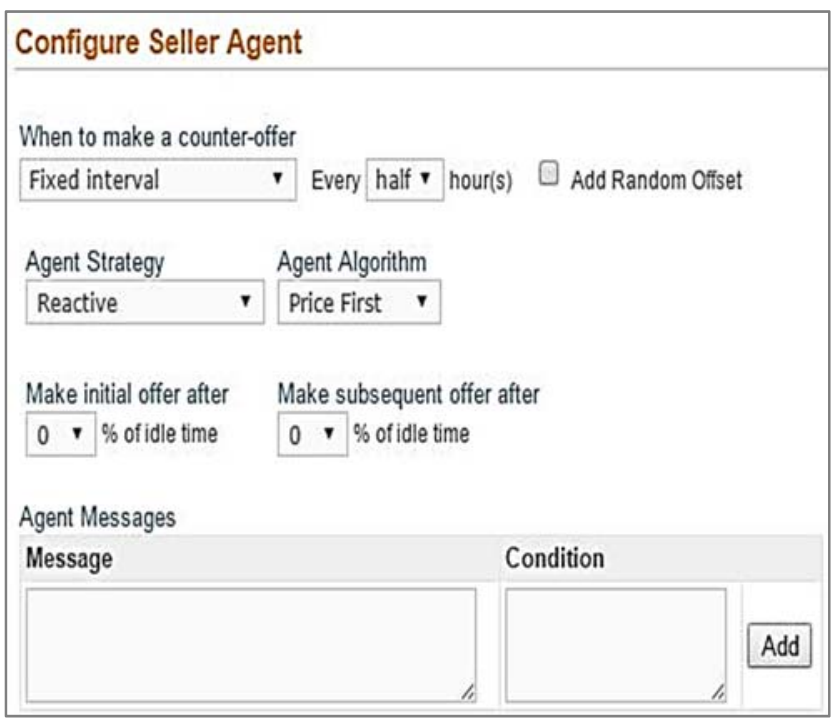

Figure 2. Strategy configuration

Strategy configuration included the following three components: (1) the specification of the timing of the first and subsequent offers; (2) the way the agent considered the human negotiator's offers in the computation of the counteroffer offers; and (3) the messages that the agent sent (with or without offers) when the message condition was met.

With each strategy, a time-dependent concession function was associated, they jointly represent the complete strategy. The concession curve was modeled using Bezier curves. The concession schedule associated with pure strategy was modeled with:

$$
B(t)=(1-t)^{2} P_{0}+2(1-t) t P_{1}+\mathrm{t}^{2} P_{2} ;
$$

and the concession schedule associated with mixed strategy was modeled with

$$
B(t)=(1-t)^{3} P_{0}+3(1-t)^{2} t P_{1}+3(1-t) t^{2} P_{2}+t^{3} P_{3}:
$$

where $\mathrm{t} \in[0,1], P_{1}, P_{2}, P_{3}$ and $P_{4}$ are points used to define the max, min and curvature of the curve (indicated as dots in Figs. 3 and 4).

Competitive agents tend to make smaller concessions in terms of the utility of generated offers in the beginning of 
the negotiations. However, as they approach the negotiation deadline, they begin making larger concessions in search of an agreement. These agents are expected to have the highest utility of agreement levels, perhaps at the expense of the number of agreements.

Compromising agents tend to make large concessions in the very beginning of the negotiation period in an attempt to reach agreement quickly. This represents the case where an agent is anxious to sell the plan. Compromising agents are not expected to have high utility value deals, although they are more likely to make an agreement.

Concessions schedules for the two pure strategies are shown in Fig. 3.

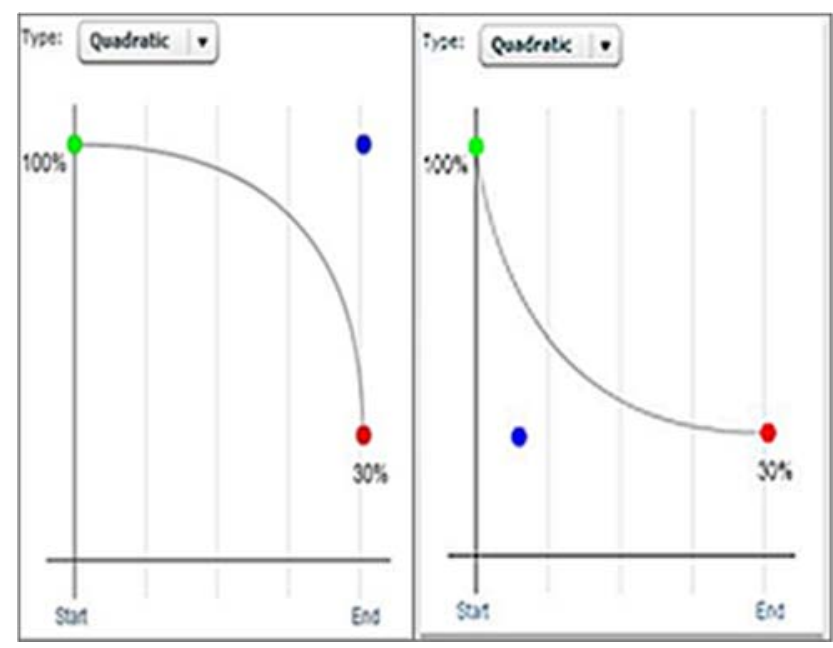

Figure 3. Competitive and compromising schedules

The two remaining strategies comprise a mix of the competitive and compromising schedules. Part of the guidelines for agent tactics design were outlined in [7], as mentioned in the background section suggested: making a tough initial offer; making monotonously decreasing concessions; making large concession in the final offer.

The compromising-competitive schedule mimics this sort of behavior. It starts with the tough offer, then makes quick concessions. These become smaller with time to make an opponent think that the agent is reaching its reservation level. If the counterpart does not propose a good offer for the agent, then the agent makes another small concession in an effort to reach an agreement.

The competitive-compromising strategy starts out tough in the hopes of grabbing high-value deals. However, if an agreement is not reached in the initial phases, the agent switches to compromising mode. In this way, the agent could combine the benefits of both competitive and competing tactics.

Concession schedules for the two mixed strategies are shown in Fig. 4.

\subsection{Human participants}

The subjects were recruited from university students enrolled in an online case. The case was chosen so that the subjects had a good level of familiarity with it. The case featured the sale of a mobile phone plan.

Prior to the negotiation, the case was outlined to the subjects, who could ask questions and request clarifications. We found out that most subjects were well aware of the issues involved in such plans and only a few required additional explanations.

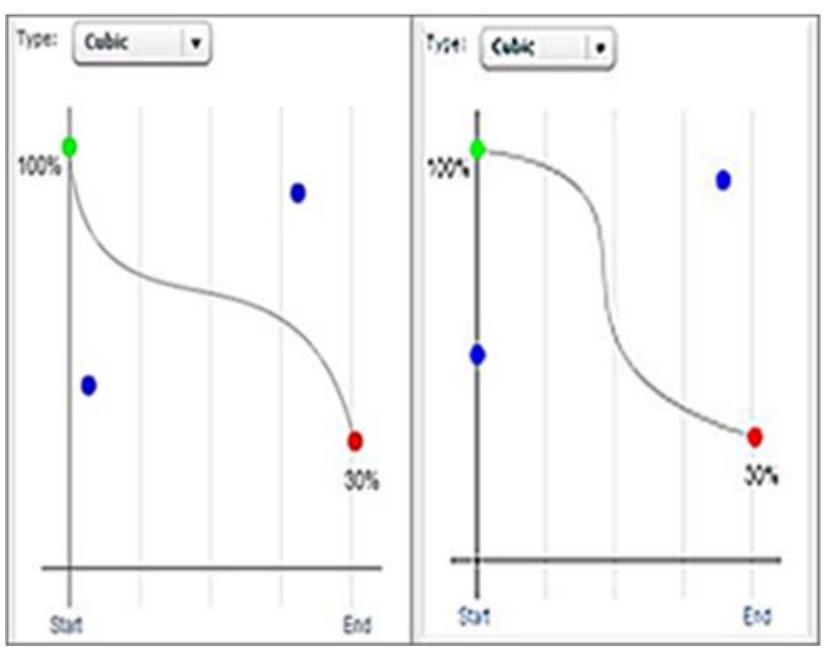

Figure 4. Compromising-then-competitive and competitive-then-compromising schedules

\subsection{Experiment}

The treatments included randomly pairing up the subjects with various types of agents in a simple or complex case as described above. The experiment was conducted on the web, whereby subjects could perform their tasks from any location in an asynchronous mode during a two-day period. The subjects were invited to join the negotiations via emails containing the link to the system. Human subjects were free to terminate the negotiation at any time without reaching an agreement.

All agents acted on the seller side and they were not aware of the buyers' preferences. The buyers' and the sellers' preference weights were somewhat different in order to promote tradeoffs, which have been considered one of the key activities necessary to reach an efficient agreement.

The preferences were specified and fixed for all human users. This was done in order to control variation in the experiments.

\section{Results}

A total of 754 subjects have participated in the experiment 
and have completed the experimental task. For the analysis of the results we have selected only those subjects who made more than one offer to filter out the cases where subjects did not take the experimental case seriously. After filtering the number of subjects dropped to 368 . Based on these retained observations, 262 negotiations (71\%) ended up in an agreement, while 106 (29\%) dyads did not make an agreement.

\subsection{Agreement rate}

The agreement rate for the simple case setting was $75.5 \%$, while for the complex case it was $65.4 \%$. Thus, in simple case, including fewer issues, the agreements were more frequent. On one hand, a larger number of issues should give negotiators more space for "maneuvering" in negotiations, thus higher likelihood of making an agreement. On the other hand, the complexity of the case taxes cognitive capabilities of the humans and requires more cognitive effort.

In our setup, one case included five issues, while the other featured ten. This seems to be the reason why fewer agreements were made in the complex case. Table 1 displays the agreement rates for the four tactics overall, and for simple vs. complex cases separately.

\section{Table 1. Agreement rates for different agent types}

\begin{tabular}{|c|c|c|c|}
\hline Strategy & Simple case & Complex case & Overall \\
\hline Competitive & $57.1 \%$ & $48.9 \%$ & $53.6 \%$ \\
\hline Compromising & $87.7 \%$ & $85.3 \%$ & $87.0 \%$ \\
\hline $\begin{array}{l}\text { Compromising } \\
- \text { Competitive }\end{array}$ & $83.8 \%$ & $70.0 \%$ & $75.9 \%$ \\
\hline $\begin{array}{c}\text { Competitive }- \\
\text { Compromising }\end{array}$ & $71.0 \%$ & $60.0 \%$ & $66.1 \%$ \\
\hline
\end{tabular}

As one can see from the table, the highest agreement rates were achieved by the compromising agents, and the lowest one by the competitive agents. This is not surprising given their concession schedules the other two agent types are in between the extremes. However, compromisingcompetitive agents seem to have been able to make more agreements than the competitive-compromising ones. Thus, apparently the guidelines for agent design seem to be having a positive impact in terms of the likelihood of an agreement.

Case complexity does not seem to have a large effect on the agreement rate for the compromising agents. This makes sense, as the agent concedes so quickly that agreements are reached early regardless the complexity of the case. It does seem to have a larger impact when an agent is competitive. The implication here is that competitive agents are more likely to make an agreement in simpler cases. Interestingly, the biggest difference in terms of agreement rate is for the compromising-competitive agents. For simple cases their agreement rate approaches the rates for the compromising agent.

\subsection{Sellers' strategy and agreement utility}

Next, we analyze the agent performance in terms of the seller utility of the achieved agreements. For this analysis only the instances where the agreement was achieved were included to enable calculation of the utilities. A general linear model was built incorporating agent types and the complexity level for predicting the obtained utilities. Number of offers was included as a co-variate as it represented effort and time spent in the negotiation instances.

Multivariate tests showed that the case complexity, agent type, and number of offers were all significant at $p=$ 0.05 level. Furthermore, the interaction of case complexity and agent type was also significant. Table 2 shows the results of utility calculations for different agent types.

\section{Table 2. Sellers' average agreement utility for different concession schedules}

\begin{tabular}{|l|c|c|c|}
\hline \multicolumn{1}{|c|}{ Concession } & Simple case & Complex case & Overall \\
\hline Competitive & 81.42 & 61.55 & 73.67 \\
\hline Compromising & 47.05 & 45.96 & 46.74 \\
\hline $\begin{array}{l}\text { Compromising } \\
- \text { Competitive }\end{array}$ & 54.16 & 49.86 & 51.88 \\
\hline $\begin{array}{l}\text { Competitive - } \\
\text { Compromising }\end{array}$ & 53.26 & 46.33 & 50.45 \\
\hline Average & 57.02 & 50.87 & 54.62 \\
\hline
\end{tabular}

The sellers achieved higher final utility in the simple case setting than in the complex case setting (61.5 and 52.4 respectively).

Overall, competitive agents achieved agreements with the highest utility, followed by the compromising-competitive, competitive-compromising, and lastly, compromising agents. Complexity of the case has the largest impact for competitive agents, medium impact for the compromising-competitive and competitive-compromising agents, and virtually no impact for the compromising agents.

\subsection{Sellers' utility}

The competitive strategy may produce the highest agreement's utility for individual agents but the agreements are achieved in the smallest number of the negotiations; $57.1 \%$ of the competitive agents achieved an agreement in the simple case and $48.9 \%$ in the complex case (see Table 1).

From the perspective of a business that employs selling agents the average utility per seller is more important criterion because it determines the total utility (profit). Table 3 shows the average utility of an agreement per one seller.

For the simple case, the average utility per one seller is the highest for the competitive strategy followed by compromising-competitive strategy. For the complex case, interestingly, agents that employ the compromising strategy 
achieve the highest utility value, followed by agents employing the compromising-competitive strategy.

Table 3. Average utility per seller

\begin{tabular}{|l|c|c|c|}
\hline \multicolumn{1}{|c|}{ Concession } & Simple case & Complex case & Overall \\
\hline Competitive & 46.52 & 30.12 & 39.52 \\
\hline Compromising & 41.24 & 39.20 & 40.60 \\
\hline $\begin{array}{l}\text { Compromising } \\
\text { - Competitive }\end{array}$ & 45.38 & 34.90 & 39.36 \\
\hline $\begin{array}{l}\text { Competitive - } \\
\text { Compromising }\end{array}$ & 37.80 & 27.80 & 33.34 \\
\hline Average & 42.73 & 33.01 & 38.21 \\
\hline
\end{tabular}

Based on these results, we can say that a business that does not distinguish between simple and complex negotiation cases should employ equipped selling agents with the compromising strategy because on average it produces higher utility than the agents that use competitive strategy. The latter is very closely followed by compromising-competitive strategy that produces results. Overall, these three strategies yielded much higher utility, compared to the competitive-compromising strategy.

\subsection{Buyers' utility}

This work focuses on the agent performance in two different settings and the implication of their use of different negotiation strategies on the agreement's utility. In the case of single-shot negotiations and when reputation has no impact on the negotiators' behavior one-sided focus may be sufficient. If, however sellers engage in repeated negotiations and/or reputation plays a role, then the results achieved by the other-side are likely to play a role [40, 41]. Therefore, we briefly discuss here the results achieved by the buyers. Table 4 shows the average buyers' utility for the agreements; this table corresponds to Table 2 for the sellers.

Table 4. Buyers' average agreement utility for agent's different concession schedules

\begin{tabular}{|l|c|c|c|}
\hline Concession & Simple case & Complex case & Overall \\
\hline Competitive & 8.57 & 18.70 & 12.52 \\
\hline Compromising & 37.29 & 39.96 & 38.06 \\
\hline $\begin{array}{l}\text { Compromising } \\
\text { - Competitive }\end{array}$ & 30.39 & 19.01 & 24.35 \\
\hline $\begin{array}{c}\text { Competitive - } \\
\text { Compromising }\end{array}$ & 18.91 & 30.81 & 23.73 \\
\hline Average & 26.96 & 26.63 & 26.83 \\
\hline
\end{tabular}

Table 4 shows that the buyers achieved significantly lower utility values (all utility values were between 0 and 100). Particularly the difference for the competitive strategies is drastic: the sellers achieved 81.42 and 61.55 while the buyers achieved 8.57 and 18.7 for the simple and complex cases, respectively. The competitive-compromising strategy produced somewhat better results for the buyers but the difference is quite large. In both case types and for every strategy the sellers outperformed the buyers.

The buyers' low utility of the agreements results in poor results achieved by every buyer on average. The buyers' utilities shown in Table 5 correspond to the sellers' utilities shown in Table 3.

\section{Table 5. Average utility per buyer for agents' different concession schedules}

\begin{tabular}{|l|c|c|c|}
\hline Concession & Simple case & Complex case & Overall \\
\hline Competitive & 4.90 & 9.15 & 6.72 \\
\hline Compromising & 32.69 & 34.09 & 33.10 \\
\hline $\begin{array}{l}\text { Compromising } \\
\text { - Competitive }\end{array}$ & 25.46 & 13.31 & 18.48 \\
\hline $\begin{array}{c}\text { Competitive - } \\
\text { Compromising }\end{array}$ & 13.42 & 18.48 & 15.68 \\
\hline Average & 20.35 & 17.41 & 19.10 \\
\hline
\end{tabular}

From the results shown in Table 3 it follows that a company that would employ all the buyers participating in this experiment would obtain utility per buyer of 20.35 for the simple case and 17.41 for the complex case. This can be contrasted with a selling company that employed all the agents: it would achieve utility 43.03 for the simple case and 33.26 for the complex case. This means that the agents achieved over twice as much as the human buyers.

\section{Conclusions}

The purpose of this work was to investigate the effects of agent negotiation strategies and negotiation task complexity on agent performance in electronic negotiations. As suspected, the agents' negotiation strategies have a significant interaction with the task complexity. This difference is especially prominent for the competitive agents, as they made significantly fewer agreements and achieved significantly lower agreement utilities in complex cases. Overall, agents made $18 \%$ more agreements in negotiations involving fewer issues.

One limitation of the current research is that experiment was done online rather than in the lab setting. This reduced the potential control over the subject behavior in the experiments. Furthermore, the time span allocated for the experiment (two days) may have affected the results achieved by the human buyers. Future in-lab experiments preceded with a quiz that assess the participants' understanding of the case and the task should be undertaken to overcome these limitations. We also plan to varying levels of complexity, for example, by including a single issue, three issues, five issues, and ten issues. 
Another limitation is that we consider one-shot negotiations. When the transactions between sellers and buyer repeat over time, then the sellers may employ strategies that are likely to create a relationship with the buyers so that they are more likely to engage in future negotiations. In situations when repeat sales are unlikely, this limitation may be of lesser importance.

A related limitation is due to the lack of competition. The buyers could not terminate their negotiations with one seller and initiate change with another seller. One extension may be an experiment in which the buyers have more flexibility and may negotiate with several sellers sequentially or simultaneously. A more complex experiment is an online market situation that is similar to a stock exchange and in which one seller may negotiate with multiple buyers and one buyer - with multiple sellers.

\section{Acknowledgements}

This work has been supported by the grant from Royal Bank of Canada and Concordia University.

\section{References}

[1] Kersten, G. E. and Noronha, S. Negotiations via the World Wide Web: A Cross-cultural Study of Decision Making. Group Decision and Negotiations, 8 (1999), 251-279.

[2] Saade, R., Vahidov, R. and Yu, B. Agents and Ecommerce: Beyond Automation. Porto Rico, 2015.

[3] Blanning, R. W. and Bui, T. X. Decision Support Systems and Internet Commerce. Springer, New York, 2000.

[4] Maes, P., Guttman, R. H. and Moukas, A. G. Agents that Buy and Sell. Communication of the ACM, 42, 3 (1999), 81-91.

[5] Greenwald, A., Jennings, N. R. and Stone, P. Agents and markets. IEEE Intelligent Systems, 18, 6 (2003), 12-14.

[6] Lin, R. and Kraus, S. Can Automated Agents Proficiently Negotiate with Humans? Communications of the ACM, 53, 1 (2010), 78-88.

[7] Yang, Y., Singhal, S. and Xu, Y. C. Offer with Choices and Accept with Delay: A Win-Win Strategy Model for Agent Based Automated Negotiation. AIS, Manchester, 2009.

[8] Vahidov, R., Saade, R. and Yu, B. Effects of negotiation tactics and task complexity in software agent: human negotiations. ACM, Boston, 2016.

[9] Chavez, A., Dreilinger, D., Guttman, R. and Maes, P. A Real-life Experiment in Creating and Agent Marketplace. Springer, Haidelberg, 1997.

[10] Chavez, A. and Maes, P. Kasbah: An agent marketplace for buying and selling goods. London, UK, 1996.

[11] Faratin, P., Sierra, C. and Jennings, N. R. Negotiation Decision Functions for Autonomous Agents. Robotics and Autonomous Systems, 24 (1998), 159-182.

[12] Kersten, G. E. and Lo, G. Aspire: Integration of Negotiation Support System and Software Agents for E-
Business Negotiation. International Journal of Internet and Enterprise Management, 1, 3 (2003), 293-315.

[13] Chen, E., Vahidov, R. and Kersten, G. E. Agent-supported Negotiations on E-marketplace. International Journal of Electronic Business, 3, 1 (2005), 28-49.

[14] Vahidov, R., Chen, E. and Kersten, G. Experimental assessment of agent-supported electronic negotiations. International Journal of Human-Computer Interaction, 29, 11 (2013), 764-774.

[15] Lang, F. and Fink, A. Learning from the metaheuristics: Protocols for automated negotiations. Group Decision and Negotiation, 24, 2 (2015), 299-332.

[16] Fujita, K., Ito, T., Zhang, M. and Robu, V. (eds.) Next Frontier in Agent-based Complex Automated Negotiation. Springer, 2015.

[17] Sycara, K. Multi-agent compromise via negotiation. Distributed artificial intelligence, 2, 1 (1989), 119-139.

[18] Rosenschein, J. S. and Zlotkin, G. Rules of Encounter. The MIT Press, London, 1994.

[19] Dillenbourg, P. and Baker, M. Negotiation spaces in human-computer collaborative learning. COOP'96, INRIA, Juan-les-Pins, 1996.

[20] Kraus, S. and Lehmann, D. Designing and building a negotiating automated agent. Computational Intelligence, 11, 1 (1995), 132-171.

[21] Klein, G., Woods, D. D., Bradshaw, J. M., Hoffman, R. R. and Feltovich, P. J. Ten challenges for making automation a" team player" in joint human-agent activity. IEEE Intelligent Systems, 19, 6 (2004), 91-95.

[22] Raiffa, H. The Art and Science of Negotiation. Harvard University Press, Cambridge, MA, 1982.

[23] Byde, A., Yearworth, M., Chen, K.-Y. and Bartolini, C. AutONA: A system for automated multiple 1-1 negotiation. ACM CEC, San Diego, 2003.

[24] Huang, S.-1. and Lin, F.-r. The design and evaluation of an intelligent sales agent for online persuasion and negotiation. Electronic Commerce Research and Applications, 6, 3 (2007), 285-296.

[25] de Melo, C. M., Carnevale, P. and Gratch, J. The effect of expression of anger and happiness in computer agents on negotiations with humans. AAMAS '11, 3, Richland, 937944, 2011.

[26] Vahidov, R., Kersten, G. and Saade, R. An experimental study of software agent negotiations with humans. Decision Support Systems, 66 (2014), 135-145.

[27] Vahidov, R., Kersten, G. E. and Gimon, D. Interaction between Software Agent-Enabled System with Invite ENS users: Multi-Bilateral Negotiations., Recife, 2012.

[28] Thompson, L. The Mind and Heart of the Negotiator. Prentice Hall, Upper Saddle River, 2005.

[29] Craver, C. B. Effective Legal Negotiation and Settlement. Lexis, Dayton, 2001.

[30] Blake, R. and Mouton, J. S. The Managerial Grid. Gulf, Houston, 1964.

[31] Korobkin, R. and Guthrie, C. Heuristics and Biases at the Bargaining Table. Marquette Law Review, 87 (2003), 795808. 
[32] Vetschera, R., Kersten, G. E. and Koeszegi, S. The Determinants of NSS Success: An Integrated Model and Its Evaluation. Journal of Organizational Computing and Electronic Commerce, 16, 2 (2006), 123-148.

[33] Benbasat, I. and Lim, L.-H. The effects of group, task, context, and technology variables on the usefulness of group support systems A meta-analysis of experimental studies. Small Group Research, 24, 4 (1993), 430-462.

[34] Skehan, P. A cognitive approach to language learning. Oxford University Press, 1998.

[35] De Dreu, C. K. W. and Weingart, L. R. Task versus Relationship Conflict, Team Performance, and Team Member Satisfaction: A Meta-analysis. Journal of Applied Psychology, 88, 4 (2003), 741.

[36] Prietula, M. J. and Weingart, L. R. Negotiation Offers and the Search for Agreement. Negotiation and Conflict Management Research, 4, 2 (2011), 77-109.
[37] Hyder, E. B., Pietrula, M. J. and Weingart, L. R. Getting to Best: Efficiency versus Optimality in Negotiation. Cognitive Science, 24, 2 (2000), 169-204.

[38] Fatima, S. S., Wooldridge, M. and Jennings, N. R. An agenda-based framework for multi-issue negotiation. Artificial Intelligence, 152, 1 (2004), 1-45.

[39] Weingart, L. R., Bennett, R. J. and Brett, J. M. The Impact of Consideration of Issues and Motivational Orientation on Group Negotiation Process and Outcome. Journal of Applied Psychology, 78, 3 (1993), 504-517.

[40] Guttman, R. H. and Maes, P. Cooperative vs. Competitive Multi-Agent Negotiations in Retail Electronic Commerce. Springer, City, 1998.

[41] Tinsley, C. H., Cambria, J. and Schneider, A. K. Reputations in Negotiation. American Bar Association, San Francisco, 2007. 